\title{
Pengaruh Asam Itakonat terhadap Properti Polimer Perekat Akrilik Berbasis Air
}

\author{
[Effect of Itaconic Acid on the Properties of Acrylic Water Base Adhesive \\ Polymer]
}

\author{
Rony Pasonang Sihombing*, Agustinus Ngatin
}

Department of Chemical Engineering, Politeknik Negeri Bandung

\begin{abstract}
Acrylic-based polymer adhesive is a type of adhesive that can be used for pressure sensitive adhesive (PSA). Itaconic acid (IA) is a type of acid with 2 (two) $\mathrm{OH}$ groups which can form hydrogen bonds. The acrylic base can be used purely from its class. In some cases, however, the acrylic base can be used together with another base. Therefore acrylic-based adhesive with variable addition of itaconic acid was introduced in this study. In this application, the holding power property is one of the important parameters of a PSA. Therefore, holding power is the main parameter in this study. This research includes the preparation of tools and materials, mixing the main raw materials of acrylic monomer and itaconic acid with the types of surfactants and water, and product characterization. The polymerization process is carried out at a pressure of $1 \mathrm{~atm}$ with a temperature of $75^{\circ} \mathrm{C}$ $80^{\circ} \mathrm{C}$ accompanied by stirring with a rotation rate of $\pm 500 \mathrm{rpm}$. The characterization of this research resulted in a PSA product with a holding power of $2 \mathrm{~kg}$ for 30 seconds to 620 minutes. While the resulting peel strength is 1.12 $\mathrm{kgf} /$ inc to $0.76 \mathrm{kgf} / \mathrm{inc}$.
\end{abstract}

Keywords: itaconic acid, acrylic PSA, holding power

Abstrak. Polimer perekat berbasis akrilik merupakan jenis perekat yang dapat digunakan untuk pressure sensitive adhesive (PSA). Asam Itakonat (IA) merupakan jenis asam dengan 2 (dua) ikatan $\mathrm{OH}$ yang dapat membentuk ikatan hidrogen. Basis akrilik dapat digunakan secara murni dari kelasnya. Namun pada beberapa kasus, basis akrilik dapat digunakan bersama dengan basis lain. Untuk itu perekat berbasis akrilik dengan variabel penambahan asam itakonat diperkenalkan pada penelitian ini. Dalam aplikasinya, properti kekuatan tarik merupakan salah satu parameter penting pada sebuah PSA. Oleh karenanya, kekuatan tarik menjadi parameter utama dalam penelitian ini. Penelitian ini meliputi tahap persiapan alat dan bahan, pencampuran bahan baku utama monomer akrilik dan asam itakonat bersama jenis surfaktan serta air, dan karakterisasi produk. Proses polimerisasi dilakukan pada tekanan $1 \mathrm{~atm}$ dengan temperatur $75^{\circ} \mathrm{C}-80^{\circ} \mathrm{C}$ disertai pengadukan dengan laju putaran $\pm 500 \mathrm{rpm}$. Karakterisasi dari penelitian akhir ini menghasilkan produk PSA dengan kekuatan gaya gantung beban $2 \mathrm{~kg}$ selama 30 detik hingga 620 menit, sedangkan kekuatan tarik yang dihasilkan sebesar 1,12 kgf/inc hingga 0,76 kgf/inc.

Kata kunci: asam itakonat, PSA akrilik, holding power.

Diterima: 26 April 2021, Disetujui: 12 Juli 2021

Sitasi: Sihombing, R P., dan Ngatin, A. (2021). Pengaruh Asam Itakonat terhadap Properti Polimer Perekat Akrilik Berbasis Air. KOVALEN: Jurnal Riset Kimia, 7(2): 98-102.

\section{LATAR BELAKANG}

Beberapa cara dapat dilakukan untuk melakukan penyatuan dua substrat yang berbeda. Salah satunya adalah dengan

\footnotetext{
* Corresponding author

E-mail: rony.pasonang.sihombing@polban.ac.id
}

menggunakan jenis perekat. Di Indonesia, terutama dalam dunia industri, perekat yang masih banyak berkembang merupakan perekat berbasis pelarut organik. Jenis perekat ini tidak aman bagi lingkungan dan juga kesehatan (Cho et al., 2016). 
Pelaku dunia industri perekat di Indonesia mengalami peningkatan dari tahun ke tahun. Hal ini menyebabkan tingkat penyerapan tenaga kerja yang juga semakin meningkat setiap tahun. Berdasarkan data Kemenperin, dapat dilihat pada Tabel 1 bahwa peningkatan kebutuhan perekat di Indonesia semakin meningkat (Kemenperin, 2014 dalam Sihombing \& Ngatin, 2019).

Tabel 1. Perkembangan Jumlah Tenaga Kerja dan Jumlah Pelaku Industri Perekat di Indonesia

\begin{tabular}{ccc}
\hline $\begin{array}{c}\text { Tahun/ } \\
\text { keterangan }\end{array}$ & $\begin{array}{c}\text { Jumlah } \\
\text { tenaga } \\
\text { kerja } \\
\text { (orang) }\end{array}$ & $\begin{array}{c}\text { Jumlah } \\
\text { industri } \\
\text { (unit) }\end{array}$ \\
\hline 2008 & 4000 & 40 \\
2009 & 4100 & 41 \\
2010 & 4300 & 47 \\
2011 & 5900 & 47 \\
2012 & 6300 & 48 \\
2013 & 6700 & 49 \\
\hline
\end{tabular}

Polimer perekat berbasis akrilik merupakan salah satu jenis perekat yang dapat digunakan untuk kelas perekat yang disebut Pressure Sensitive Adhesive (PSA). Kelas ini banyak digunakan pada aplikasi sehari-hari seperti lakban/ isolasi, label, kertas catatan, dan masih banyak lagi (Yuan et al., 2017). Kelebihan dari PSA ini adalah material ini hanya membutuhkan sedikit tekanan untuk penggunaannya (Creton, 2003) dan juga dapat digunakan dengan monomer jenis lain untuk menghasilkan karakter yang lebih baik. Secara umum biasanya asam akrilat digunakan sebagai monomer dalam pembuatan perekat akrilik. Pada penelitian ini, asam itakonat (IA) digunakan untuk menggantikan asam akrilat pada pembuatan perekat akrilik dengan pertimbangan adanya 2 (dua) ikatan $\mathrm{OH}$ yang akan dapat membentuk ikatan hidrogen dengan substrat (Creton, 2003; Handayani et al., 2013).

Monomer asam akrilik adalah senyawa kimia dengan rumus kimia $\mathrm{CH}_{2}=\mathrm{CHCOOH}$. Monomer ini merupakan turunan ester yang digunakan untuk manufaktur polimer superabsorban, plastik, karet buatan, fplastik, perekat (Sun et al., 2017). Struktur senyawa molekul asam akrilik terdapat pada Gambar 1.

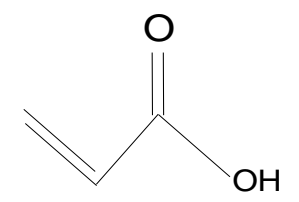

Gambar 1. Senyawa monomer asam akrilik

Monomer asam itakonat merupakan padatan putih yang larut dalam air, etanol dan aseton. Senyawa ini memiliki dua gugus fungsi $\mathrm{OH}$ yang dapat digunakan untuk membentuk ikatan hidrogen yang akan menghasilkan karakter baru dari sebuah polimer. Struktur senyawa ini dapat dilihat pada Gambar 2 (Teleky \& Vodnar, 2019).

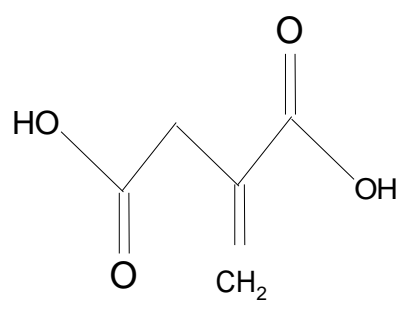

Gambar 2. Struktur dasar asam itakonat

Pembuatan perekat akrilik melibatkan keberadaan radikal bebas untuk membantu konversi monomer menjadi polimer. Sumber radikal bebas pada polimerisasi emulsi yakni berupa inisiator. Inisiator menginisiasi pembentukan polimer pada reaksi polimerisasi adisi monomer-monomer (Putri, 2008). Inisiator berkaitan dengan jumlah radikal bebas yang terbentuk. Oleh karena itu, inisiator memiliki peranan penting untuk membentuk radikal bebas (Sunardi et al., 2013). Pada penelitian 
ini, digunakan Inisiator Amonium Persulfate (APS) sebagai perantara oksidasi yang sangat kuat. APS bersifat inisiator radikal juga sebagai katalis yang sangat kuat. Penambahan inisiator APS akan menghasilkan radikal bebas pada gugus fungsional, khususnya dari material anorganik yang digunakan dan membentuk radikal yang sangat reaktif sehingga monomer dapat bergabung menjadi polimer. Sifat-sifat amonium persulfat tersaji pada Tabel 4 (Sentra Informasi Keracunan Nasional, 2011)

Produk yang dihasilkan dar ipenelitian ini adalah sebuah perekat akrilik. Perekat akrilik merupakan senyawa polimer termoplastik yang memilki sifat tahan panas, daya regang tinggi serta larut dalam pelarut organik. Industri perekat akrilik banyak digunakan pada aplikasi PSA. Biasanya perekat jenis ini dibuat dengan monomer Butil Akrilat (BA), 2-Etil Heksil Akrilat (2-EHA), asam, Metil Metakrilat (MMA).

\section{METODE PENELITIAN}

\section{Bahan dan Peralatan}

Bahan yang digunakan pada penelitian ini antara lain aquades, surfaktan, monomer (2EHA, BA, IA) dan aditif. Sedangkan alat yang digunakan antara lain reaktor, thermometer, pengaduk, corong tetes, buret, kondensor dan water bath.

\section{Prosedur Penelitian}

\section{Proses Polimerisasi}

Proses polimerisasi akan dilakukan di dalam reaktor dengan kondisi dialirkan gas nitrogen (inert). Kecepatan pengadukan akan dilakukan di angka 50 - 500 rpm (opsional) dan akan menggunakan pemanasan dari water bath.

Dimulai dari pembuatan pre-emulsi yang terdiri dari air, surfaktan dan monomer 2-EHA, BA dan IA. Kemudian pre emulsi dimasukkan secara bertahap bersamaan dengan larutan APS ke dalan reaktor. Suhu dijaga pada rentang $75^{\circ} \mathrm{C}-80^{\circ} \mathrm{C}$ hingga akhir feeding. Setelah feeding selesai, pengadukan dibiarkan selama waktu tertentu untuk stabilitas produk, kemudian suhu diturunkan ke dalam suhu ruang dan produk dapat diambil (Athawale \& Kulkarni, 2009).

\section{Skema Polimerisasi}

Reaktor dilengkapi dengan kodensor, feeding system, kontrol suhu dan pengaduk. Hal ini dapat dilihat pada skema yang diilustrasikan pada Gambar 3.

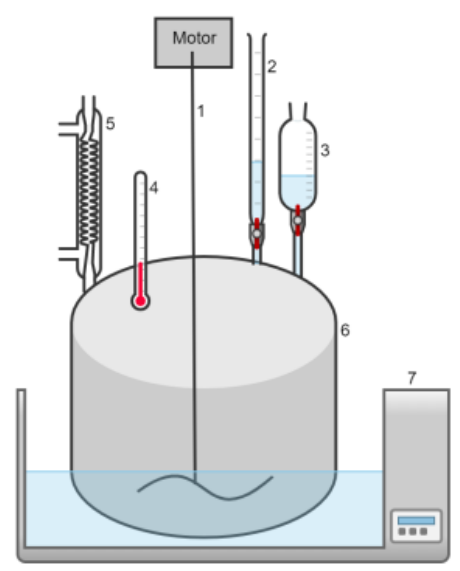

Gambar 3. Kondisi operasi polimerisasi

Keterangan:
1) Pengaduk
2) Buret
3) Droping funel
4) Termometer
5) Kondensor
6) Reaktor
7) Water bath

\section{HASIL DAN PEMBAHASAN}

Penelitian dilakukan dengan membuat beberapa sampel melalui sintesis polimerisasi PSA akrilik dalam beberapa konsentrasi IA. Hasil pengujian holding power dan peel strength ditampilkan pada Gambar 4 dan Gambar 5. 


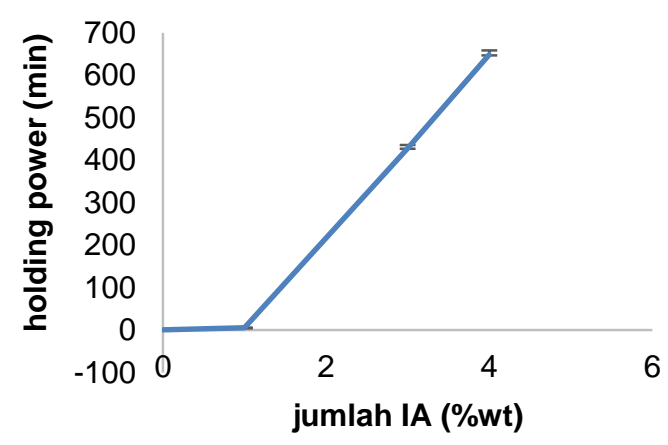

Gambar 4. Pengaruh IA terhadap properti holding power

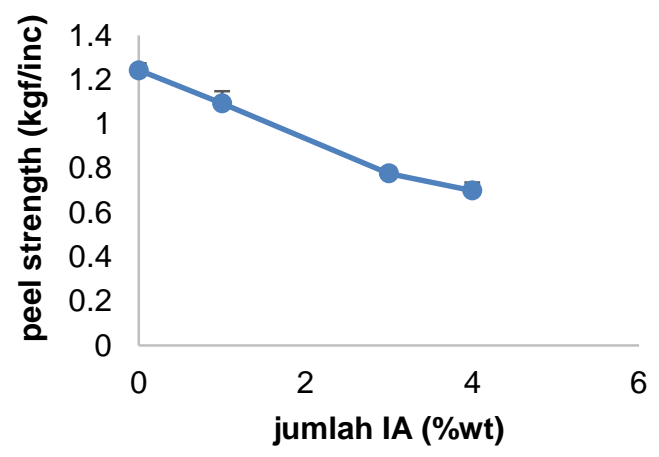

Gambar 5. Pengaruh IA terhadap properti peel strength

Pada Gambar 4 dapat dilihat bahwa semakin banyak jumlah IA, semakin tinggi nilai holding power. Uji holding power merupakan uji kekuatan tarik (geser) pada PSA. Semakin tinggi nilai uji holding power, semakin rekat ikatannya. Hal ini dikarenakan karena adanya dua gugus $\mathrm{OH}$ pada struktur IA yang menyebabkan lebih banyaknya ikatan hidrogen (da Cruz et al., 2017). Hal ini berdampak pada kekuatan tariknya. Hasil uji ini menunjukkan fenomena peningkatan hingga lebih dari $200 \%$ jika dibandingkan penelitian sejenis yang menggunakan asam akrilat (Ghim \& Kim, 2016)

Pada Gambar 5 dapat dilihat bahwa semakin banyak jumlah IA, semakin kecil nilai peel strength. Nilai peel strength ini mewakili nilai kupasan dimana material akan ditarik dengan sudut $180^{\circ}$. Nilai yang dihasilkan untuk holding power dan peel strength pada PSA biasanya berbanding terbalik. Hal ini dikarenakan pada PSA, angka nilai peel strength diharapkan sekecil mungkin (Yuan et al., 2017).

Berdasarkan Gambar 4 dan Gambar 5, PSA hasil penelitian didapatkan hasil standar deviasi yang relatif kecil. Hal ini dikarenakan karena ikatan alil yang ada pada IA. Ikatan alil atom hidrogen akan dapat bergerak menyebabkan monomer transfer dan terbentuknya radikal IA yang dapat menyusun molekul secara intramolekuler untuk membentuk radikal alil yang stabil (Bednarz et al., 2017). Hal ini dapat dilihat pada skema ilustrasi Gambar 6.

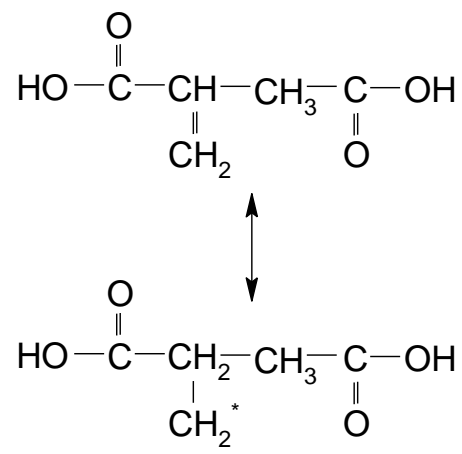

Gambar 6. Skema ilustrasi ikatan alil pada asam itakonat

\section{KESIMPULAN}

Sintesis polimer PSA akrilik telah berhasil dibuat dengan polimerisasi air - surfaktan monomer menggunakan APS sebagai inisiatornya. Penambahan IA berpengaruh pada karakter holding power dan peel strength PSA. Peningkatan jumlah IA berdampak pada peningkatan nilai holding power dan berdampak pada penurunan nilai peel strength.Untuk proses aplikasi, diharapkan dapat memanfaatkan hasil penelitian ini untuk mengatur fenomena nilai uji yang diinginkan sesuai penggunaan. 


\section{UCAPAN TERIMA KASIH}

Kami ucapkan terima kasih kepada Politeknik Negeri Bandung atas dukungannya.

Penelitian ini dibiayai oleh Politeknik Negeri Bandung melalui Skema Penelitian Mandiri Surat Perjanjian nomor 105.126/PL1.R7/PG.00.03/2021

\section{DAFTAR PUSTAKA}

Athawale, V. D., \& Kulkarni, M. A. (2009). Preparation and properties of urethane/acrylate composite by emulsion polymerization technique. Progress in Organic Coatings, 65(3): 392-400.

Bednarz, S., Półćwiartek, K., Wityk, J., Strachota, B., Kredatusová, J., Beneš, H., Wesołowska-Piętak, A., \& Kowalski, G. (2017). Polymerization-crosslinking of renewable itaconic acid in water and in deep eutectic solvents. European Polymer Journal, 95: 241-254.

Cho, U. R., Oh, J. H., Kim, J. H., \& Jung, H. J. (2016). A Study on the Synthesis and Properties of Environmental Friendly Pressure Sensitive Adhesive for Manufacturing Electronic Products. 15(1): 12-16.

Creton, C. (2003). Pressure-sensitive adhesives: An introductory course. MRS Bulletin, 28(6): 434-439.

da Cruz, J. C., Camporese Sérvulo, E. F., \& de Castro, A. M. (2017). Microbial Production of Itaconic Acid. In Microbial Production of Food Ingredients and Additives (Issue November). Elsevier Inc.

Ghim, D., \& Kim, J. H. (2016). Effects of composition and layer thickness of a butyl acrylate/acrylic acid copolymer on the adhesion properties. Korean Journal of Chemical Engineering, 33(2): 707-710.

Handayani, F. W., Muhtadi, A., Farmasi, F., Padjadjaran, U., Dara, T., Manis, K., \& Aktif, S. (2013). Penggunaan Monomer Asam Itakonat pada Molecularly Imprinted Polymer (MIP). Farmaka, 4: 115.
Putri, kurnia syah. (2008). Studi Optimasi Polimerisasi Metil Metaklirat - Pengaruh Variasi Konsentrasi Inisiator Amonium Persulfat, Monomer Metil Metaklirat Dan Surfaktan. Skripsi. Universitas Indonesia, Depok.

Sentra Informasi Keracunan Nasional. (2011). Amonium sulfat. 213.

Sihombing, R P. \& Ngatin, A. 2019. Modifikasi Homopolimer Poli (Vinil Asetat) Dengan Variabel Hidrofobisitas Emulsifier Untuk Aplikasi Perkayuan. Jurnal Fluida, 12(2): $72-77$

Sun, D., Yamada, Y., Sato, S., \& Ueda, W. (2017). Glycerol as a potential renewable raw material for acrylic acid production. Green Chemistry, 19(14): 3186-3213.

Sunardi, Irwan, A., Nurjannah, \& Istikowati, W. T. (2013). Pengaruh Penambahan Jumlah Inisiator Amonium Persulfat (APS) Terhadap Karakteristik Polimer Superabsorben Asam Akrilat Dan Selulosa Batang Alang-Alang (Imperata cylindrica). Posiding Seminar Nasional Penelitian, Pendidikan Dan Penerapan MIPA Fakultas MIPA, Universitas Negeri Yogyakarta, ISBN : 978 - $979-96880-7$ - 1, 18 May, 127-132.

Teleky, B. E., \& Vodnar, D. C. (2019). Biomassderived production of itaconic acid as a building block in specialty polymers. Polymers, 11(6).

Yuan, Y., Zhang, Y., Fu, X., Kong, W., Liu, Z., Hu, K., Jiang, L., \& Lei, J. (2017). Molecular design for silane-terminated polyurethane applied to moisture-curable pressure-sensitive adhesive. In Journal of Applied Polymer Science, 134(37). 